\title{
Do Extraversion, Agreeableness, Openness to Experience, Conscientiousness and Neuroticism Relate to Students Academic Achievement: The Approach of Structural Equation Model and PROCESS Macro
}

\author{
Francis Britwum $^{1 *}$, Samuel Obed Amoah², Henry Yaw Acheampong², Elizabeth Adoma \\ Sefah $^{2}$, Esther Twewa Djan ${ }^{3}$, Barimah Solomon Jill ${ }^{4}$, and Sandra Aidoo ${ }^{5}$ \\ ${ }^{* 1}$ University of Cape Coast, Department of Education and Psychology. \\ ${ }^{2}$ St. Monica's College of Education, Department of Education Studies. \\ ${ }^{3}$ Berekum College of Education. Department of Education Studies. \\ ${ }^{4}$ University of Cape Coast, Department of Guidance and Counselling. \\ ${ }^{5}$ University of Cape Coast, Department of Home Economics. Ghana \\ DOI - http://doi.org/10.37502/IJSMR.2022.5205
}

\begin{abstract}
The study examined how personality trait relates to academic achievement of College of Education students in Ghana. The descriptive cross-sectional survey design within the positivist paradigm was employed. A multi-stage sampling procedures were used in the sample selection process. In all, 325 students were selected from six Colleges of Education to participate in the study. An instrument was used to collect the data from the respondents and was tested using inferential statistics such Structural Equation Model and Process Analysis. The findings showed that extraversion, agreeableness, conscientiousness and neuroticism were not predictors of academic achievement of the students. Openness to experience was the only predictor of students' academic achievement. The result discovered that gender does not moderate the relationship between subdimensions of personality trait and academic achievement of the students. The study recommended that school officials, educators, and parents should think about how vital it is to understand students' personality qualities. This is due to the fact that each student is unique and has various characteristics. It is therefore, essential to study each individual in order to meet their needs.
\end{abstract}

Keywords: Personality trait (extraversion, agreeableness, openness to experience, conscientiousness and neuroticism) and Academic Achievement.

\section{Introduction}

Individual differences are important in educational psychology, especially when it comes to how they affect students' academic achievement. People differ in their actions, feelings, and reactions to situations, which could be due to personality variations (Gana, Oluwafeyisayomi, \& Idowu, 2020). In other words, anything that influences student's mental effectiveness affects their 
academic progress and habits. As a result, in order to improve academic achievement among college of education students, it is necessary to look into some of the intrinsic unique qualities of students that are linked to their academic achievement.

Students, tutors, university lecturers and education officers would agree that college of education student success or achievement is determined by multiple factors, such as students' attitudes and interests, class attendance, study behaviours, management of conflicting roles, time management, and coordination and cooperation with other students (Agormedah, Britwum, Amoah, Acheampong, Adjei, \& Nyamekye, 2021; Dollinger, Huber, \& Matyja, 2008). These factors influence students' academic achievement, which is a critical outcome that determines graduation status, college admission, and employment prospects. Other important student characteristics, such as leadership, civic engagement, and interpersonal skills, are also predicted by these variables (Elias \& Haynes, 2008). In respect to academic achievement, Usman (2015). Opined that academic achievement is the outcome of education, the extent to which a student has achieved his/her educational goals. It means that, academic achievement is commonly measured by examinations and what the student can do in the school and outside the school with the knowledge he or she has acquired. Academic achievement are scores students obtained from external examinations. The scores students obtain usually reflect individual differences in academic ability or the level of mastery of individuals on a given task (Gana, Oluwafeyisayomi, \& Idowu, 2020). In order to find out what is responsible for fluctuating students' academic achievement it has become necessary to find out if personality trait (extraversion, agreeableness, openness to experience, conscientiousness and neurotic) has a positive or negative effects on student academic achievement.

In 1937, Gordon Allport defined personality as "the dynamic arrangement of those psychophysical systems within the individual that determine a distinctive adaption to the environment." Personality refers to a pattern of ideas, feelings, and behaviours that distinguishes one person from another and endures through time and in different situations (Phares, 1991). Personality traits are defined as the variations in an individual's frequency and intensity of thinking, acting, and feeling in specific ways (Fleeson \& Gallagher, 2009; McAdams \& Pals, 2006). Patterns of behaviour, motivation, emotion, and cognition that are largely stable in an individual are referred to as personality traits (McCrae \& Costa, 1999) Personality traits, according to Agbakwuru (2000, p. 351), are "consistent distinctions between the behaviours and characteristics of two or more people." Individual differences factors like self-concept, motivation, emotional intelligence, creativity, and positive thinking have all been linked to academic achievement by researchers (Eyon, David, \& Umoh, 2014; Ciorbeaa \& Pasarica, 2013). According to Singh (2014), students differ in terms of their values, hence a combination of personality traits is required for an individual to succeed academically.

Majority of studies has explored personality trait with learning styles (Elahi, Braunhofer, Ricci, \& Tkalcic, 2013; Trompf, \& Brown, 2014), technology usage (Skues, Williams, \& Wise, 2014), academic motivation (Neuenschwander, Cimeli, Röthlisberger, \& Roebers, 2013) and very lightly has been discussed with academic achievement, while using gender as a moderator variable 
between the sub-dimensions of personality trait and academic achievement, which this study intends to achieve. Moreover, the link between personality traits and students' academic achievement has usually been explored among university students (Khan, 2018). And very limited has been discussed in the context of College of Education students in Ghana. Hence this study aims to address this gap in the literature by examining how personality traits relates to students' academic achievement with the use of Structural Equation Model and Process Macro.

\section{Related Studies}

According to Farsides and Woodfield (2003), the role of each of the five qualities in determining academic achievement has yielded inconsistent results. For instance, neuroticism predicted greater marks in middle school but poorer grades in college; similarly, extraversion predicted higher grades in middle school but lower grades in college (De-Raad, 1996).

Empirical studies by McAbee and Oswald (2013), O'Connor and Paunonen (2007), Poropat (2009) found conscientiousness to be the strongest and most consistent Big Five personality trait for predicting students' academic achievement. Unlike conscientiousness, popular measures of the Big Five personality traits of extraversion, agreeableness, neuroticism and openness demonstrate inconsistent and often practically no significant relationships with students' academic achievement (McAbee \& Oswald, 2013). Noftle and Robins (2007) studied the relationship between personality trait and academic aptitude and achievement. They found a positive association between conscientiousness and openness to experience to have a positive relationship with students' academic achievement.

Martey and Aborakwa-Larbi (2016) investigated the effects of personality factors (extroversion, neuroticism, openness to experience, agreeableness, and conscientiousness) on academic performance among tertiary students. Academic performance had a relationship with personality trait of conscientiousness, agreeableness, and openness to experience, according to the data. However, extroversion and neuroticism showed no relationship.

Personality qualities and their impact on academic performance among potential teachers were researched by Nordin, Ismail, Saleh, and Nasir (2020). This study enlisted the participation of 130 teachers and students. The hypotheses were tested using correlation and multiple regression. The data revealed that conscientiousness and extroversion had weak and favorable effects on academic performance. However, the findings revealed that there was a weak but inverse link between neuroticism and academic performance. Interesting, multiple regression analysis found that conscientiousness contributed about $11.8 \%$ of variance in academic performance.

Gana, Oluwafeyisayomi, and Idowu (2020) investigated the impact of personality factors on secondary school students' English language proficiency. The study used a descriptive survey research design. To pick 300 respondents, simple random sample procedures was utilized. The study's findings demonstrated that students' performance was influenced by their openness to experiences and extraversion personality qualities. Neuroticism, agreeableness, and conscientiousness were not found to be predictors of student success. 
With a sample of 273 students from the University of Ghana, Legon, Nyarko, Kugbey, Amissah, Ansah-Nyarko, and Dedzo (2016) explored the relationship between students' personality characteristics, motivation, and academic accomplishment. For the study, a crosssectional survey approach was used, and students were given standardized questionnaires that measured personality traits, intrinsic and extrinsic motivations. The only trait that strongly predicted students' academic accomplishment was conscientiousness, according to the findings.

Khan (2018) investigated how extraversion, agreeableness, conscientiousness, emotional stability, and openness to experience influence MBA students' academic performance. A total of 706 students were used in the study. The data was analyzed using the T-test and the Mann Whitney $\mathrm{U}$ test. Academic performance was significantly influenced by conscientiousness, extraversion, and agreeableness. Emotional stability and openness to experience, on the other hand, were not found to be predictive of students' academic performance.

Nguyen et al. (2005) looked into students' personality traits, gender, and academic performance. Gender moderated the association between personality trait and academic performance, according to the study. Khan (2020) looked at gender variations in the impact of personality factors on academic performance. A total of 666 students (453 men and 213 females) were used in the study. Using Mann-Whitney analysis, it was discovered that distinct personality factors have an impact on both males and females' academic performance. Male students' academic performance was found to be influenced by extraversion, conscientiousness, agreeableness, and emotional stability. Openness, on the other hand, had an impact on female students' academic performance. Conscientiousness was the only personality attribute that had an impact on both male and female students' academic performance.

Gender variations in the five-component model of personality and sensation seeking were investigated by Rahmani and Lavasani (2012). A total of 177 undergraduate students were chosen (108 females and 69 males). Female and male students showed significant differences in the big five personality characteristics, according to the data. In comparison to boys, girls scored much better on openness to experience and agreeableness.

Costa, Terracciano, and McCrae (2021) looked into gender disparities in personality traits across cultures and came up with some interesting results. According to the findings, women claimed higher levels of neuroticism, agreeableness, warmth, and openness to experience, while men reported higher levels of assertiveness and openness to experience. Feingold (1994) utilized meta-analysis to corroborate Maccoby and Jacklin's (1974) findings on gender differences in adult personality traits and to investigate other gender differences in normative data from the most extensively used personality questionnaire. According to the findings, women scored lower on assertiveness than males while scoring higher on extroversion, anxiety, trust, and tendermindedness.

Based on the prevailing literature, majority of the previous studies were conducted in Western and accordingly, their findings are likely to be less applicable in the Ghanaian context because personality trait, behaviours and academic achievement among students are likely to differ between Ghana and these countries due to diverse cultures, values, and beliefs (Agormedah, 
Britwum, Amoah, Acheampong, Adjei, \& Nyamekye, 2021) and there is uncertainty as to whether gender moderate the relationship between personality trait and academic achievement among students. To fill this gap in the existing literature, the present examination proposed the following research hypothesis:

\section{Hypotheses}

1. H0: Personality trait (extraversion, agreeableness, openness to experience, conscientiousness and neurotic) will not predict students' academic achievement in the Colleges of Education in Ghana

H1: Personality trait (extraversion, agreeableness, openness to experience, conscientiousness and neurotic) will predict students' academic achievement in the Colleges of Education in Ghana

2. H0: Gender will not moderate the relationship between personality trait and students' academic achievement in the Colleges of Education in Ghana

H1: Gender will moderate the relationship between personality trait and students' academic achievement in the Colleges of Education in Ghana.

\section{Theoretical Framework}

The Five Factor model (FFM) (Costa \& McCrae, 1992a; Goldberg, 1993; John \& Srivastava, 1999) has gained a widespread acceptance regarding the science of personality traits. FFM (also called the Big Five which will be used interchangeably throughout this thesis) is as hierarchical model of personality traits with five basic factors (Costa \&McCrae, 1992a). They include extraversion, agreeableness, and openness to experience, conscientiousness and neuroticism.

People that are extraverted are gregarious, chatty, forceful, active, ambitious, and expressive (Barrick \& Mount, 1991). Extraversion is characterized by a strong desire to engage with the outside world. Extraverts like social situations, they have a lot of energy and are frequently filled with happy feelings. They are inclined to say yes to exciting chances because they are actionoriented, bring attention to themselves, forceful, and enthusiastic (Friedman \& Schustack, 2016). People who are agreeable are polite, trusting, flexible, cooperative, soft-hearted, forgiving, goodnatured, and tolerant (Barrick \& Mount, 1991). People that are agreeable also have a positive outlook on life. They feel that individuals are inherently trustworthy, nice, and honest (Barrick \& Mount, 1991). As a result, those who are agreeable are willing to sacrifice their enjoyment for the sake of others.

People with openness to experience are imaginative, inquiring, creative, original, clever, broad-minded, and artistically sensitive (Barrick \& Mount, 1991; Colquitt, Le-Pine, \& Wesson, 2009). When compared to closed people, open people are more aware of their sentiments. They have a tendency to think and act in unconventional and individualistic ways (Friedman \& Schustack, 2016). Conscientiousness people are hardworking, thorough, organized, responsible, care, reliable, ambition, and perseverance (Barrick \& Mount, 1991; Colquitt, 2009). Conscientious 
people reach high levels of accomplishment by deliberate planning, patience, and perseverance (Colquitt, Le-Pine, \& Wesson, 2009). Anxiety, depression, emotionality, anger, embarrassment, worry, and insecurity are all characteristics of people with neuroticism (Barrick \& Mount, 1991). Neurotic people have inadequate social skills and avoid situations that require them to exert control. Individuals who have a high level of neuroticism are less emotionally stable and are more prone to experience a variety of emotions (Friedman \& Schustack, 2016). Additionally, there are suggestions that the five factors are divided into two higher meta traits, where neuroticism, agreeableness and conscientiousness are said to belong to the meta trait of stability, whereas extraversion and openness are said to belong to the meta trait plasticity (DeYoung, 2010). Harnessing these traits among students could bring meaningful learning and can influence students' academic achievement in the College of Education in Ghana.

\subsection{Conceptual Framework}

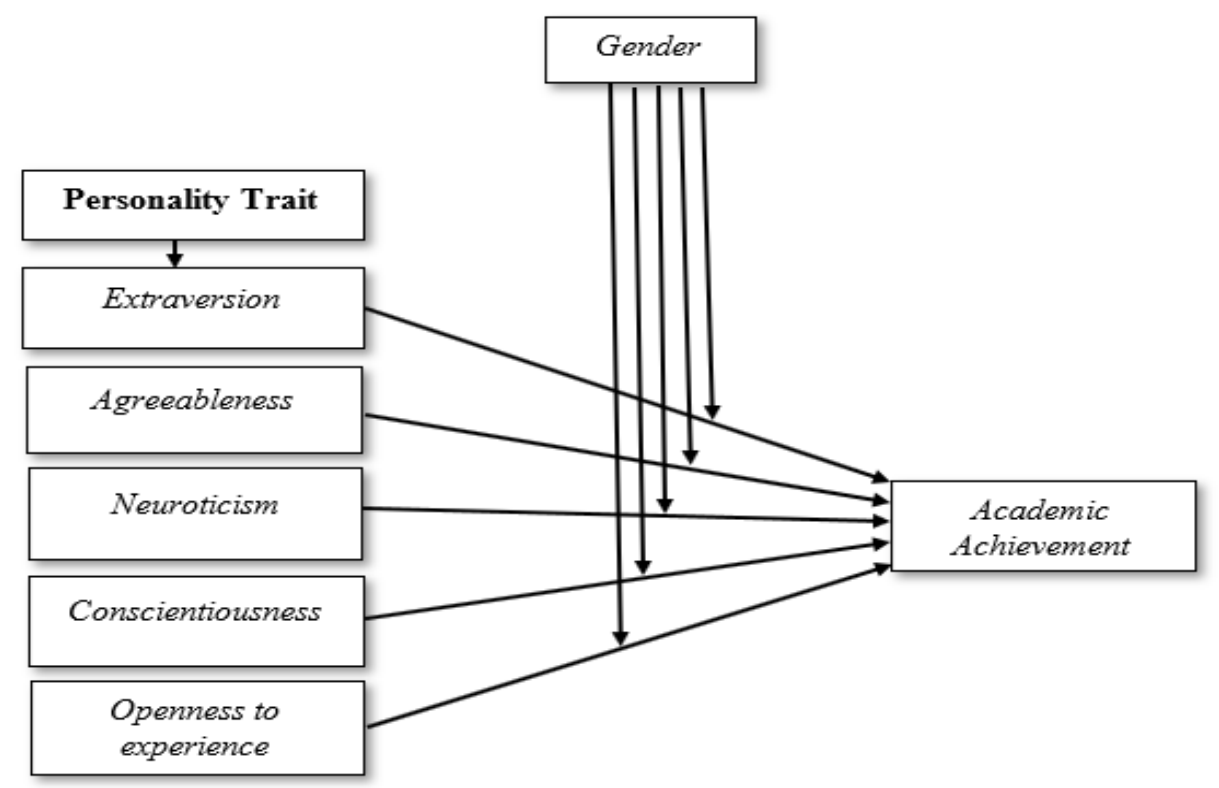

Figure 1 - Conceptual framework showing moderating role of gender in the relationship between sub-dimensions of personality trait and Academic Achievement.

\section{Methodology}

The descriptive survey design was used to conduct this research. "The descriptive survey entails gathering data in order to test hypotheses or answer research questions concerning the current status of the subject of study," according to Gay (2004, p. 187). It also describes and forecasts occurrences without affecting the variables that determine the phenomenon (Amedahe, 2002). According to Polit and Hunger (1995), a descriptive survey primarily focuses at describing, observing, and documenting characteristics of a situation as it occurs. According to Leedy and Ormond (2005), descriptive survey design entailed gathering information on one or more cohorts or groups of people, most likely on the basis of their uniqueness, views, character, or prior 
occurrence or understanding, through inquiries and pictorially presenting their responses. A descriptive survey, according to Kothari (2004), is concerned with describing, recording, assessing, and reporting situations that exist or existed. According to Kerlinger (1973), descriptive surveys are commonly used to acquire data useful in evaluating current practices and forming the foundation for choices. The descriptive survey was chosen as the best method for conducting this study since it provided the researcher with a lot of data from a large sample (Fraenkel \& Wallen, 2000). Descriptive survey design aids in the identification of trends in attitudes and behaviors, as well as the generalization of research findings (Neuman, 2000). The descriptive survey is also suited for performing this study since descriptive research involves describing, recording, evaluating, and interpreting existing conditions, and the information gained from descriptive research can be valuable or useful in diagnosing a situation.

\subsection{School Selection}

The study's target population was all Ghanaian College of Education students. In Ghana, there are forty-six (46) Colleges of Education (Institute of Education, 2021). There are five zones in which public Colleges of Education are located namely, Northern Zone have 10 Colleges of Education, the Ashanti/Brong Ahafo Zone have Colleges of Education, the Volta Zone also have 7 Colleges of Education, the Eastern/Greater Accra Zone have 9 Colleges of Education and the Central/Western Zone which also have 7 Colleges of Education. The accessible population for the study was level 300 students from 6 Colleges of Education in Ghana which amount to 2,160 (Institute of Education, 2021). In the selection procedure, multi-stage sampling techniques were applied. The overall number of Colleges of Education to be picked from each of the zones were determined using a proportionate sampling technique. Following that, the Colleges of Education were chosen using simple random sampling. To determine the total number of students to pick from the Colleges of Education, the proportionate sampling technique was utilized once more. Thereafter, simple random sampling specifically, the table of random numbers were used to select the students. In all 325 students were selected based on Krejcie and Morgan (1970) sampling size determination table.

\subsection{Data Collection Instrument and Analysis}

The Big Five Inventory scale by John and Srivastava (1999) was adopted and used in the study The scale has 44-item which was measured on a 5-point Likert scale format ranging from "Strongly Disagree" to "Strongly Agree". The Croncbach's Alpha reliability for Big Five Inventory scale was .91. Students' achievement test scores were taken from Institute of Education, University of Cape Coast. Structural Equation Model (SEM) and Process Analysis by Hayes were used to test the hypotheses.

\section{Results}

\subsection{Hypothesis One}


H0: Personality trait will not predict students' academic achievement in the College of Education in Ghana

The main aim of the hypothesis was to examine how personality trait (extraversion, agreeableness, openness to experience, conscientiousness, and neuroticism) will predict students' academic achievement in the College of Education in Ghana. Covariance-based Structural Equation Modeling (SEM) was performed to test data on this hypothesis. The analysis was performed using Analysis of Moment Structures (AMOS) software version 26. Specifically, 5000 bootstrap samples, with bias-corrected and accelerated confidence intervals was performed. Figure 2 presents the model.

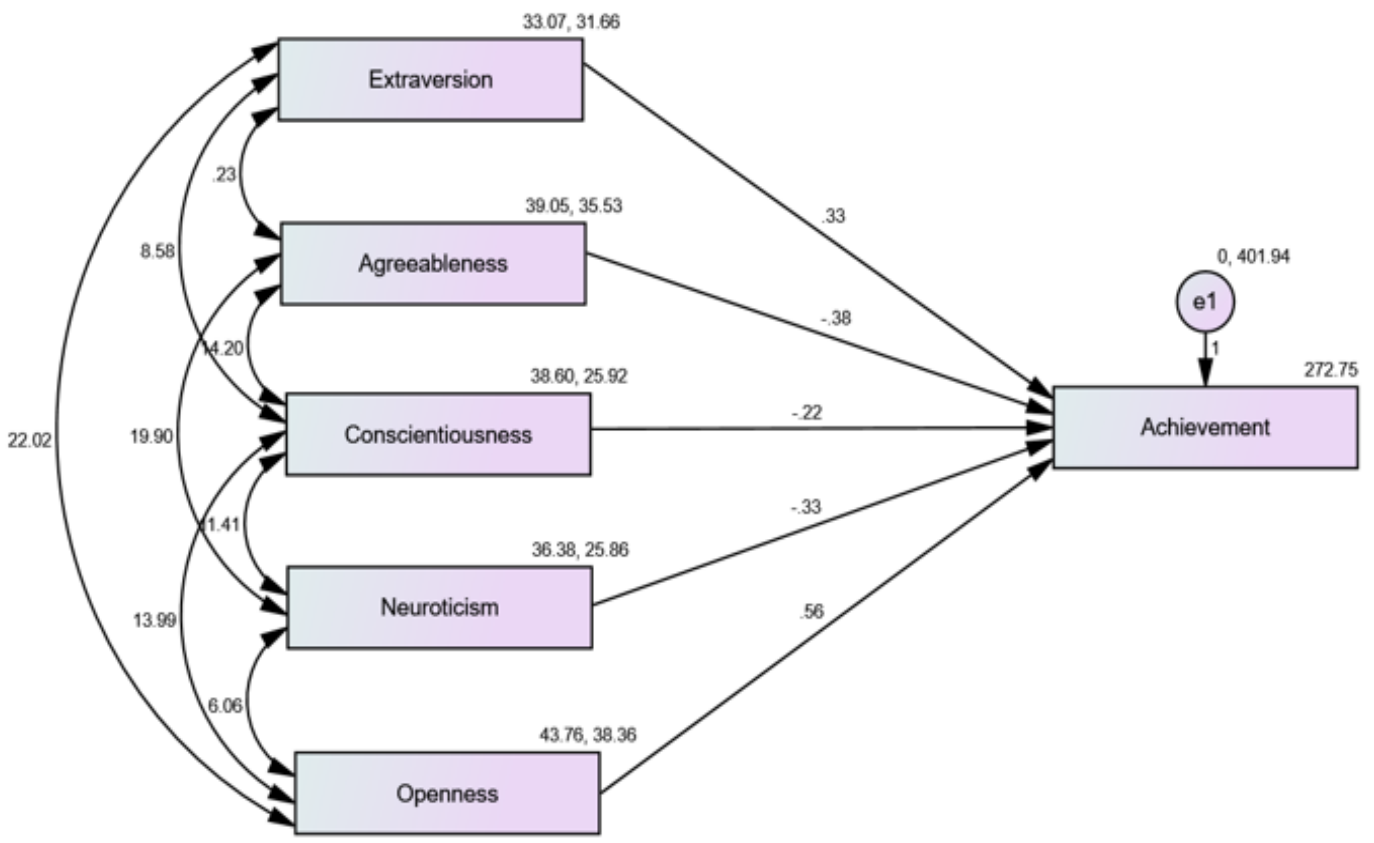

Figure 2 Path model of personality trait (extraversion, agreeableness, conscientiousness, neuroticism and openness to experience) and Academic achievement.

As presented in the path analysis (Figure 2), extraversion predict academic achievement by .33 with a mean and error variance of $(33.07,31.66)$, followed by agreeableness which also predict academic achievement by -.38 with a mean and error variance of $(39.05,35.53)$. Further, conscientiousness predicts academic achievement by -.22 with a mean and error variance of (26.60, 25.92), neuroticism predict academic achievement by -.33 with a mean and error variance of $(36.38,25.86)$. Openness to experience predict academic achievement by .56 with a mean and error variance of $(43.76,38.36)$ and an intercept of 272.75 for academic achievement. Table 1 presents the significance of the path model. 
Table 1: Regression Model for Personality trait

\begin{tabular}{lcccccc}
\hline & & & & & \multicolumn{2}{c}{$95 \%$ Confidence Interval } \\
\cline { 6 - 7 } Model & $B$ & $S E$ & $C R$ & $P$-value & Lower & Upper \\
\hline (Constant) & 272.750 & 8.577 & 21.652 & .000 & 255.876 & 289.624 \\
Extraversion & .327 & .283 & 1.297 & .212 & -.230 & .885 \\
Agreeableness & -.378 & .323 & -1.388 & .166 & -1.013 & .258 \\
Conscientiousness & -.218 & .290 & -.873 & .447 & -.789 & .352 \\
Neuroticism & -.326 & .335 & -1.140 & .291 & -.986 & .333 \\
Openness & .558 & .316 & 2.066 & .034 & .049 & 1.179 \\
\hline Source: Field data, 2021 & & & & *Significant, $\mathrm{p}<.05 ; \mathrm{R}^{2}=.020$
\end{tabular}

From Table 1, the results of the SEM shows that the model was saturated and that the model partially fits the data. Personality trait (extraversion, agreeableness, conscientiousness, neuroticism and openness to experience) jointly explained $2 \%$ of the variations in academic achievement of the students. The results showed that extraversion $[b=.327$, Boot $95 \% C I(-.230$, $.885)]$, Agreeableness $[b=-.378$, Boot $95 \% C I(-1.013, .258)]$, Conscientiousness $[b=-.218$, Boot95\%CI $(-.789, .352)]$ and Neuroticism $[b=-.326$, Boot $95 \% C I(-.986, .333)]$ were not significant predictors of academic achievement of the students. Openness $[b=.558$, Boot $95 \% C I$ $(-.049,-1.179)]$ was significant predictor of academic achievement of College of Education students. However, Extraversion, Agreeableness, Conscientiousness and Neuroticism were not necessarily predictors of academic achievement of the students.

\subsection{Hypothesis two}

H0: Gender will not moderate the relationship between personality trait and students' academic achievement in the College of Education in Ghana

This hypothesis examined whether gender moderate the link between personality trait and students' academic achievement. Moderation analysis was conducted to find out if a third variable (i.e., gender) could strengthen or weaken the relationship between a predictor (i.e., personality trait) and an outcome variable (i.e., academic achievement). The predictor was personality trait and the criterion variable was academic achievement. The analysis highlighted five models. The moderator (i.e., Gender) was used to moderate the relationship between Extraversion and academic achievement, Agreeableness and academic achievement, Conscientiousness and academic achievement, Neuroticism and academic achievement and Openness and academic achievement. The data was analysed using Hayes PROCESS Macro with 5000 bootstrap samples, using a 95\% confidence interval. The results are presented in Table 2.

Table 2: Model Summery

\begin{tabular}{lcccccc}
\hline Model & $\mathrm{R}$ & $\mathrm{R}-$ Square & $\mathrm{F}$ & $\mathrm{df1}$ & $\mathrm{df2}$ & $\mathrm{P}$ \\
\hline 1 & .3020 & .0912 & 10.7355 & 3.0000 & 321.0000 & .0000 \\
2 & .3021 & .0913 & 10.7493 & 3.0000 & 321.0000 & .0000 \\
3 & .2948 & .0869 & 10.1864 & 3.0000 & 321.0000 & .0000 \\
4 & .3007 & .0904 & 10.6382 & 3.0000 & 321.0000 & .0000 \\
5 & .2960 & .0876 & 10.2738 & 3.0000 & 321.0000 & .0000 \\
\hline
\end{tabular}

* Significant, $\mathrm{p}<0.05$. 
From Table 2, model 1, the R-Square value was .0912 which accounted for $9.12 \%$ of the variance in the self-reported academic achievement of the students. It was again, revealed that model 1 , was significant, $\mathrm{F}(3,321)=10.7355, \mathrm{p}=.0000$. In model 2 , the results was significant $\mathrm{F}(3,321)=10.7493$ and the R-Square accounted for $9.13 \%$ of the variance in the self-reported academic achievement of the students. In model 3, the R-Square value was .0869 which accounted for $8.69 \%$ of the variance in the self-reported academic achievement of the students. It was again, revealed that the model was significant, $\mathrm{F}(3,321)=10.1864, \mathrm{p}=.0000$. The results in model 4 was significant $F(3,321)=10.6382, p=.0000$ in which the R-Square accounted for $9.04 \%$ of the variance in the self-reported academic achievement of the students. The final model of the RSquare accounted for $8.76 \%$ of the variance in the self-reported academic achievement of the students. The model revealed statistical significant, $\mathrm{F}(3,321)=10.2738, \mathrm{p}=.0000$. Table 3 present the details of each model.

Table 3: Moderating Role of Gender in the Relationship between Personality Trait and Students' Academic Achievement.

\begin{tabular}{llcccccc}
\hline Model & Variable & B & SE & t-value & $\begin{array}{c}\text { p- } \\
\text { value }\end{array}$ & BootLL & BootUL \\
\hline 1 & (Constant) & 237.1974 & 20.2773 & 11.6977 & .0000 & 197.3042 & 277.0907 \\
& Extraversion & .5534 & .6143 & .9008 & .3684 & -.6553 & 1.7620 \\
& Gender & 27.5894 & 13.5482 & 2.0364 & .0425 & .9349 & 54.2440 \\
& (E)*(G) & -.4490 & .3982 & -1.1274 & .2604 & -1.2324 & .3345 \\
\hline 2 & (Constant) & 256.0598 & 22.4245 & 11.4188 & .0000 & 211.9423 & 300.1774 \\
& Agreeableness & -.0142 & .5718 & -.0248 & .9802 & -1.1390 & 1.1107 \\
& Gender & 17.8413 & 14.4094 & 1.2382 & .2166 & -10.5074 & 46.1901 \\
& (A)*(G) & -.1361 & .3632 & -.3747 & .7081 & -.8506 & .5784 \\
\hline 3 & (Constant) & 251.8633 & 23.1132 & 10.8969 & .0000 & 206.3908 & 297.3358 \\
& Conscientiousness & .1038 & .5895 & .1760 & .8604 & -1.0561 & 1.2636 \\
& Gender & 14.5106 & 14.3038 & 1.0145 & .3111 & -13.6305 & 42.6516 \\
& (C)*(G) & -.0592 & .3669 & -.1614 & .8719 & -.7810 & .6626 \\
\hline 4 & (Constant) & 267.5256 & 22.5440 & 11.8668 & .0000 & 223.1730 & 311.8783 \\
& Neuroticism & -.3314 & .6170 & -.5371 & .5916 & -1.5452 & .8825 \\
& Gender & 9.7603 & 14.7669 & .6610 & .5091 & -19.2919 & 38.8124 \\
& (N)*(G) & .0754 & .3991 & .1890 & .8502 & -.7098 & .8606 \\
\hline 5 & (Constant) & 260.8708 & 22.8917 & 11.3959 & .0000 & 215.8341 & 305.9075 \\
& Openness & -.1112 & .5204 & -.2138 & .8309 & -1.1351 & .9126 \\
& Gender & 6.8950 & 14.9216 & .4621 & .6443 & -22.4615 & 36.2515 \\
& $(\mathrm{O})^{*}(\mathrm{G})$ & .1192 & .3358 & 3551 & .7228 & -.5415 & .7800 \\
\hline
\end{tabular}

* Significant, $\mathrm{p}<0.05$.

Table 3 presents results on the moderating role of gender in the relationship between subdimensions of personality trait and academic achievement of the students. In model 1, gender was not found as a significant moderator between extraversion and AA $(b=-.4490 ; S E=.3982 ; t=-$ $1.1274 ; p=.2604$, Boot $95 \%$ CI $(-.1 .2324, .3345)$. Similarly, gender was not found as a significant 
moderator between agreeableness and academic achievement $(b=-.1361 ; S E=.3632 ; t=-.3747$; $p=.7081$, Boot $95 \%$ CI $(-.8506, .5784)$. In model 3, gender was not found as a moderator between conscientiousness and academic achievement $(b=-.0592 ; S E=.3669 ; t=-.1614 ; p=.8719$, Boot95\%CI (-.7810, .6626), followed by model 4, which gender was not found as a significant moderator between neuroticism and academic achievement $(b=.0754 ; S E=.3991 ; t=-.1890 ; p$ $=.8502$, Boot $95 \%$ CI $(-.7098, .8606)$. Finally, in model 5, gender was not found as moderator between openness and academic achievement $(b=.1192 ; S E=.3358 ; t=.3551 ; p=.7228$, Boot $95 \%$ CI $(-.5415, .7800)$. The implication of the result is that gender was not a significant moderator between sub-dimensions of personality trait and academic achievement of College of Education students in Ghana. Base on the results our final model is presented below.

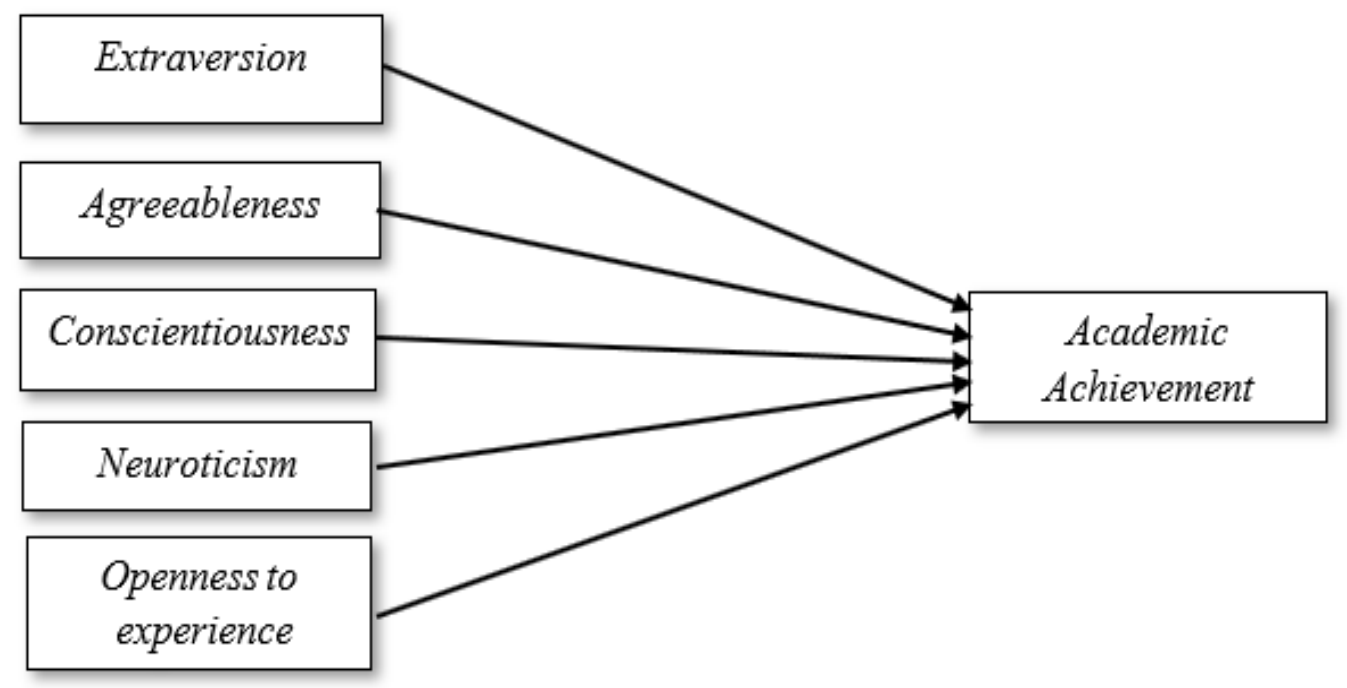

\section{Figure 3 - Final conceptual model of the relationship between sub-dimensions of personality trait and academic achievement}

\section{Discussions}

The study showed that personality trait such extraversion, agreeableness, conscientiousness and neuroticism were not significant predictors of students' academic achievement. The findings contradict those of Laidra, Pullman, and Allik (2007), who studied a large group of Estonian elementary and secondary school students. According to their findings, personality qualities such as agreeableness and conscientiousness were positively associated to students' academic achievement. Similarly, the findings contradict those of Tomsik (2018) and Komarraju, Karau, and Schmeck (2009), who reported a favorable relationship between conscientiousness and academic achievement in students. Individuals with high neuroticism scores are more likely to experience psychological distress, maladaptive and unrealistic thoughts, and are at risk of acquiring a psychiatric diagnosis, despite the fact that high scores on this domain do not imply the presence of any clinical condition. (Terracciano, Costa \& McCrea, 2006)

However, openness to experience was only the personality trait that predicted students' academic achievement in the Colleges of Education in Ghana. The study results are in line with 
studies which suggested that there is relationship between openness to experience and students' academic achievement (Paunonen \& Ashton, 2001). Duff, Boyle, Dunleavy and Ferguson (2004) investigated the effect of personality traits on students' academic achievement. The study found a slight but positive link between students' academic achievement and their openness to try new things. This association between the variables was thought to be that students who are open to new experiences are more likely to undertake academic assignments, which enhances their academic achievement. Students that are open to new experiences are seen to be more clever, creative, and hardworking. As a result of these characteristics, they are determined and committed to achieving a high academic achievement. It's not unexpected that openness to new experiences played a big role in predicting academic achievement of College of Education in Ghana.

The study again, found that gender was not a moderate between personality trait and students' academic achievement. The implication is that personality trait and students' academic achievement are similar for both male and female students. If a student has a high personality attribute, he or she is more likely to do well on academic achievement, regardless of gender. The findings of the study contradict those of Nguyen et al. (2005), who looked at gender as a moderating factor in the link between personality characteristic and student academic achievement. Gender consistently affected the association between personality and academic achievement, according to the findings. These disparities could be caused by a variety of reasons, including the study's sample, location, sampling method, or even the period it was conducted.

\section{Conclusion and Recommendations}

The results revealed that extraversion, agreeableness, conscientiousness and neuroticism were not predictors of students' academic achievement. Extroverted persons are more prone to be impatient, impulsive in problem-solving, talkative, preoccupied, and outwardly motivated, whereas neuroticism is associated with guilt, distrust, worry, fears, doubts, and other issues. These behaviours may have a negative impact on their performance, resulting in poor academic results. Despite the fact that literature has demonstrated that students who are openness and conscientious are diligent, honest, and optimistic, their personality attribute did not predict their academic achievement. It is therefore recommended that as they put much effort in working hard and being responsible, they should also work hard towards their academics in school. Again, personality trait and academic achievement were similar for both male and female students. It can be said that men and female students are getting increasingly closer to each other in their attitudes, personality traits and behavioral models.

According to the study, school officials, educators, and parents should think about how vital it is to understand students' personality qualities. This is due to the fact that each student is unique and has various characteristics. It is therefore, essential to study each individual in order to meet their needs.

\section{References}


1) Agormedah, E.K., Britwum, F., Amoah, S.O., Acheampong, H.Y., Adjei, E., \& Nyamekye, F. (2021). Assessment of Time Management Practices and Students' Academic Achievement: The Moderating Role of Gender. International Journal of Social Sciences and Educational Studies, 8(4), 171-188.

2) Amedahe, F. K. (2002). Notes on educational research. Unpublished lecture notes, University of Cape Coast.

3) Barrick, M. R., \& Mount, M. K. (1991). The big five personality dimensions and job performance: A meta-analysis. Personnel Psychology, 44(1), 1-26.

4) Ciorbeaa, I., and Pasarica, F. (2013) The study of the relationship between personality and academic performance. Procedia - Social and Behavioral Sciences, 78, 400-404

5) Colquitt, J., Le-Pine, J., \& Wesson, M. (2009). Organizational behaviour; improving performance and commitment in the workplace. New York, NY: McGraw-Hill, Irwin.

6) Costa, P. T., Terracciano, A., \& McCrae, R. R. (2021). Gender differences in personality traits across cultures: robust and surprising findings. Journal of Personality and Social Psychology, 81(2), 322-331

7) De-Raad, B., \& Schouwenburg, H. C. (1996). Personality in learning and education: A review. European Journal of Personality. 10. 303-336.

8) DeYoung, C. G. (2010). Personality neuroscience and the biology of traits. Social and Personality Psychology Compass, 4(12), 1165-1180.

9) Dollinger, S. J., Matyja, A. M., \& Huber, J. L. (2008). Which factors best account for academic success: Those which college students can control or those they cannot? Journal of Research in Personality, 42(4), 872-885. http://dx.doi.org/ 10.101 6/j .jrp.2007. 11.007.

10) Duff, A., Boyle, E., Dunleavy, K., \& Ferguson, J. (2004). The relationship between personality, approach to learning and academic performance. Personality and Individual Differences, 36, 1907-1920.

11) Elahi, M., Braunhofer, M., Ricci, F., \& Tkalcic, M. (2013). Personality-based active learning for collaborative filtering recommender systems. In Congress of the Italian Association for Artificial Intelligence (pp. 360-371). Springer International Publishing.

12) Elias, M. J., \& Haynes, N. M. (2008). Social competence, social support, and academic achievement in minority, low-income, urban elementary school children. School psychology quarterly, 23(4), 474.

13) Eyong, E. I., David, B. E., \& Umoh, A. J. (2014). The Influence of Personality Trait on the Academic Performance of Secondary School Students in Cross River State, Nigeria. Journal Of Humanities and Social Science, 19(3), 12-19

14) Farsides, T., \& Woodfield, R. (2003). Individual differences and undergraduate academic success: The roles of personality, intelligence, and application. Personality and Individual Differences, 34, 1225-1243.

15) Feingold, A. (1994). Gender differences in personality: A meta-analysis. Psychological Bulletin, 116, 429-456. 
16) Fleeson, W., \& Gallagher, P. (2009). The implications of Big Five standing for the distribution of trait manifestation in behavior: Fifteen experience-sampling studies and a meta-analysis. Journal of Personality and Social Psychology, 97(6), 1097-1114.

17) Fraenkel, J. R., \& Wallen, N. E. (2000). How to design and evaluate research in education. New York: McGraw-Hill Inc.

18) Friedman, H. S., \& Schustack, M. W. (2016). Personality: Classic theories and modern research. Boston, MA: Pearson/Allyn and Bacon.

19) Gana, S. J., Oluwafeyisayomi, A. R., \& Idowu, A. S. (2020) Influence of Personality Traits on English Language Performance of Secondary School Students in Oyo. International Journal of Research and Innovation in Social Science, 4(7), 350-355

20) Gay, L. R. (2004). Educational research ( $\left.4^{\text {th }} \mathrm{ed} /\right)$. New York: Merrill.

21) Goldberg, L. R. (1993). The structure of phenotypic personality traits. American Psychologist, 48, 26-34.

22) John, O. P., \& Srivastava, S. (1999). The Big-Five trait taxonomy: History, measurement, and theoretical perspectives. In L. A. Pervin \& O. P. John (Eds.), Handbook of personality: Theory and research (Vol. 2, pp. 102-138). New York: Guilford Press.

23) Kerlinger, F. N. (1973). Foundation of behavioral research (2nd ed.). New York: Holt Rinlialt and Winston Inc.

24) Khan, D. (2018). Study of impact of personality traits on academic performance of management students. Journal of Organisation \& Human Behaviour, 7(4), 43-56.

25) Khan, K. (2020). Gender differences in personality traits in relation to academic performance. Journal of Educational Studies, Trends \& Practices, 10(1), 124-137

26) Komarraju, M., Karau, S. J., \& Schmeck, R. R. (2009). Role of the Big Five personality traits in predicting college students' academic motivation and achievement. Learning and Individual Differences, 19, 47-52.

27) Kothari, C. R. (2004). Research methodology: Methods and techniques ( $2^{\text {nd }}$ ed.). New Delhi: New Age International Publishers.

28) Krejcie, R. V., \& Morgan, D. W. (1970). Determining sample size for research activities. Educational and Psychological Measurements, 30, 602-610.

29) Laidra, Pullman., \& Allik. (2007) Personality and intelligence as predictors of academic achievement: A cross-sectional study from elementary to secondary school. Personality and Individual Differences, 42, 441-451

30) Leedy, P. D., \& Ormrod, J. E. (2005). Practical research: Planning and design (8th ed). US, NJ: Pearson Merrill Prentice Hall.

31) Maccoby, E. E., \& Jacklin, C. N. (1974). The psychology of sex differences. Stanford, CA: Stanford University Press.

32) Martey, E. M., \& Aborakwa-Larbi, K. (2016). Assessing the impact of personality traits on academic performance: evidence from tertiary students in Ghana. Int J Res Engr IT Soc Sci, 6(3), 1-17. 
33) McAbee, S. T., \& Oswald, F. L. (2013). The criterion-related validity of personality measures for predicting GPA: A meta-analytic validity competition. Psychological Assessment, 25(2), 532-544.

34) McAdams, D. P., \& Pals, J. L. (2006). A new Big Five: Fundamental principles for an integrative science of personality. American Psychologist, 61, 204-217.

35) McCrae, R. R., \& Costa, P. T. (1997). Personality trait structure as a human universal. National Institute on Aging, 52(5), 509-516.

36) Neuenschwander, R., Cimeli, P., Röthlisberger, M., \& Roebers, C. M. (2013). Personality factors in elementary school children: Contributions to academic performance over and above executive functions? Learning and Individual Differences, 25, 118-125.

37) Nguyen, N. T., Allen L.C., \& Fraccastoro, K. (2005). Personality predicts academic performance: Exploring the moderating role of gender. Journal of Higher Education Policy and Management, 27(1), 105-117. doi: 10.1080/13600800500046313.

38) Noftie, E. E., \& Robins, R. W. (2007). Personality predictors of academic outcomes: Big five correlates of GPA and SAT scores. Journal of Personality and Social Psychology, 93(1), 116-130. http://dx.doi.org/10. 1037/0022-3514.93.1.116.

39) Nordin, N., Ismail, M. H., Saleh, M. F. M., \& Nasir, N. A. M. (2020). Assessing personality traits and its influence on academic performance among prospective teachers. International Journal of Academic Research in Business and Social Sciences, 10(14), 159-170.

40) Nyarko, K., Kugbey, N., Amissah, C. M., Ansah-Nyarko, M., \& Dedzo, B. Q. (2016). Influence of the Big Five Personality and Motivation on Academic Achievement among University Students in Ghana. British Journal of Education, Society \& Behavioural Science, 13(2), 1-7,

41) O'Connor, M. C., \& Paunonen, S. V. (2007). Big five personality predictors of postsecondary academic performance. Personality and Individual Differences, 43(5), 971-990.

42) Paunonen, S. V., \& Ashton, M. C. (2001). Big five predictors of academic achievement. Journal of Research in Personality, 35, 78-90.

43) Phares, E. J. (1991). Introduction to psychology (3rd. ed.) New York: Harper Collins Publishers.

44) Polit, D. F., \& Hungler, B. P. (1995). Nursing research: Principles and methods (5th ed). Philadelphia: Lippincott.

45) Poropat, A. E. (2009). A meta-analysis of the five-factor model of personality and academic performance. Psychological Bulletin, 135(2), 322-338

46) Rahmani, S., \& Lavasani, M. G. (2012). Gender differences in five factor model of personality and sensation seeking, Social and Behavioral Sciences, 46, 2906 - 2911.

47) Singh, S. K. (2014). Personality Traits and Academic Achievement among College Students. The International Journal of Indian Psychology, 2(1) 
48) Skues, J. L., Williams, B., \& Wise, L. (2012). The effects of personality traits, self-esteem, loneliness, and narcissism on Facebook use among university students. Computers in Human Behavior, 28(6), 2414-2419.

49) Terracciano, A., Costa, P. T. Jr. \& McCrae, R. R. (2006). Personality plasticity after age 30. Personality and Social Psychology Bulletin, 32, $999-1009$.

50) Trompf, L., \& Brown, C. (2014). Personality affects learning and trade-offs between private and social information in guppies. Animal Behaviour, 88, 99-106.

51) Usman, Y. D. (2015). The Impact of Instructional Supervision on Academic Performance of Secondary School Students in Nasarawa State, Nigeria. Journal of Education and Practice, 6(10), 160-167. 